\title{
Journal Club: Scoping review of prevalence of neurologic comorbidities in patients hospitalized for COVID-19
}

Guillermo Delgado-García, MD, Antonio Arauz, MD, PhD, and Teresa Corona, MD, MSc

Neurology ${ }^{\circledR}$ 2020;95:701-704. doi:10.1212/WNL.0000000000010534

Coronavirus disease 2019 (COVID-19) is a global pandemic. As COVID-19 cases rise in different countries, neurologists and neurologists-in-training will be increasingly involved in the care of these patients from both a general medical and neurologic perspective. In the same way, patients with preexisting neurologic conditions are in no way exempt from acquiring this infection. On the other hand, new-onset neurologic manifestations have also been recently reported in previously healthy people infected with severe acute respiratory syndrome coronavirus 2 (SARS-CoV-2). ${ }^{1}$ It is essential for neurologists and neurologists-in-training to be aware of the repercussions that COVID-19 may have in our daily practice.

Herman et al. ${ }^{1}$ recently reported a scoping review on COVID-19 and neurologic practice. This review displayed the current panorama in brief and simple terms. Its concise results are one way to continue caring for these patients in a better-informed way. Syntheses like this one are vital when evidence is rapidly changing, especially during this season when many neurologists are directly treating patients with COVID-19 and they do not have enough time to read all relevant articles coming out daily. Therefore, this Journal Club highlights 2 main teaching goals: (1) to present a summary and interpretation of this relevant article ${ }^{1}$; and (2) to discuss the methodology and value of a relatively new approach to evidence synthesis (i.e., scoping review), particularly contrasting this method with that performed in a systematic review.

\section{Hypotheses and design}

The authors detailed 2 different but related aims: (1) to evaluate the frequency of preexisting neurologic conditions in adult inpatients with COVID-19 and (2) to estimate the frequency of new neurologic manifestations in adult inpatients infected with SARS-CoV-2. ${ }^{1}$ The authors chose the scoping review as synthesis methodology. As recommended for systematic reviews, in this particular type of strategy, rather than simply describing their hypotheses, authors are advised to unambiguously state the purposes that will be addressed in their synthesis. ${ }^{2}$

Scoping reviews are one of the many methodologic approaches to knowledge synthesis. This tool is ideal to explore the scope and nature of a body of literature and provide clear indication of the studies available as well as an overview of their focus. ${ }^{3}$ Compared to systematic reviews, the most popular evidence synthesis strategy in evidence-based medicine, scoping reviews answer broader questions (e.g., extent, range, or nature of available evidence). ${ }^{2,4}$ Meta-analysis or meta-synthesis are not typically conducted as a part of scoping reviews. ${ }^{3,4}$ Additional differences between scoping and systematic reviews are summarized in the table.

Choosing the scoping review method as a means to navigate the sea of COVID-19-related evidence may reflect the diversity of the field, ${ }^{2}$ as COVID-19 is a continuously changing research

\author{
Correspondence \\ Dr. Delgado-García \\ guillermo.delgadogr@ \\ comunidad.unam.mx
}

\section{MORE ONLINE}

COVID-19 Resources

For the latest articles, invited commentaries, and blogs from physicians around the world

NPub.org/COVID19 
Table Two different knowledge syntheses: scoping vs systematic reviews

\begin{tabular}{lll}
\hline A priori review protocol & Scoping review & Systematic review \\
\hline PROSPERO registration of the review protocol & Sometimes & Yes \\
\hline Explicit, transparent, peer-reviewed search strategy & No & Yes \\
\hline Standardized data extraction forms & Yes & Yes \\
\hline Mandatory critical appraisal (risk of bias assessment) & Yes & Yes \\
\hline Synthesis of findings from individual studies and the generation of "summary" finding & $\mathrm{No}^{\mathrm{a}}$ & $\mathrm{No}^{\mathrm{b}}$ \\
\hline
\end{tabular}

Abbreviation: PROSPERO = International Prospective Register of Systematic Reviews.

Modified from reference 3 .

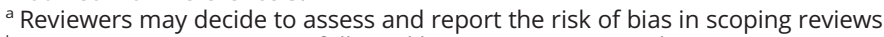

${ }^{\mathrm{b}}$ Some scoping reviews are followed by a quantitative synthesis.

topic. This strategy is often applied in emerging fields where it aims to map evidence on a particular topic. ${ }^{2}$

\section{Methods}

The article by Herman et al. ${ }^{1}$ followed the Preferred Reporting Items for Systematic Reviews and Meta-Analyses (PRISMA) Extension for Scoping Reviews (PRISMA-ScR) in general terms. ${ }^{2}$ PRISMA-ScR is intended to foster a wider understanding of key elements (such as basic terms and concepts) while reporting scoping reviews. ${ }^{2}$ Herman et al. ${ }^{1}$ systematically searched the literature using the following databases as information sources: MEDLINE, Cumulative Index to Nursing and Allied Health Literature, and Scopus. Although it may seem confusing at first glance that both systematic and scoping reviews systematically explore the specialized literature, some methodologic particularities allow us to discern between these 2 methods. ${ }^{2-4}$ For instance, compared to systematic reviews, scoping reviews have less restrictive inclusion criteria. In addition, specialized frameworks other than population, intervention, comparison, and outcome may also be used in scoping reviews (e.g., population, concept, and context) when developing research questions. Furthermore, this synthesis methodology is not restricted to any specific study design, including quantitative studies. However, the opposite is not always true, and reviewers working on a scoping review may decide to focus on a specific study design, ${ }^{2-4}$ as in the case of Herman et al., ${ }^{1}$ who only included quantitative studies.

Additional reports were retrieved by the authors through a Google-based gray literature search and snowballing. ${ }^{1}$ Versions of articles that precede formal peer review (i.e., preprints) are usually considered gray literature and were allowed by their prespecified eligibility criteria. Theses, dissertations, research, committee and government reports, conference papers, and ongoing research are also considered gray literature. Inclusion of this type of documents in a knowledge synthesis may decrease publication bias, boost timeliness and comprehensiveness, and promote a fair overview of available evidence. ${ }^{5}$
Snowballing is a manual method of scanning the reference lists of articles or pursuing references of references.

Articles reporting adult inpatients with COVID-19 and preexisting neurologic conditions or new-onset neurologic manifestations during the course of this infection were included in this scoping review but only if they were published in English. ${ }^{1}$ This language restriction is especially relevant in the present case because, at the beginning, the pandemic primarily affected non-English-speaking countries (such as China and Italy). In any evidence synthesis, exclusion of non-English language articles may decrease the generalizability and applicability of the results. It may in addition preclude the performance of future sensitivity analyses, especially those focused on assessing geographical bias. In this context, non-English language reports could also be regarded as a quality indicator. If, during the course of the review, it is not feasible to extract the information of interest from one of these non-English language reports, the most recent edition of the Cochrane Handbook for Systematic Reviews of Interventions recommends classifying this article in the PRISMA flow diagram as "studies awaiting classification" rather than "excluded studies," thus informing readers about other potentially pertinent reports. ${ }^{6}$ Focusing on scoping reviews, the JBI Reviewer's Manual also disapproves restrictions on evidence source selection by language unless a valid rationale is provided (e.g., feasibility). ${ }^{4}$

A primary literature search was designed by the authors and then at least 2 reviewers independently screened all publications (including title and abstract). If an article met inclusion criteria, one reviewer independently extracted data on comorbidity and clinical variables. ${ }^{1} \mathrm{~A}$ dual independent review of search results is associated with the identification of a higher number of relevant studies. An increase in the precision of study selection seems to be also linked with greater involvement of a second reviewer throughout the review process. ${ }^{7}$

The risk of bias across studies was not assessed by Herman et al. ${ }^{1}$ because, unlike what is recommended for systematic reviews, a risk of bias assessment is not typically conducted in 
scoping reviews. In general, this assessment is not performed since scoping reviews are not intended to be used to critically appraise a cumulative body of evidence. ${ }^{2}$ Therefore, practical implications arising from this type of knowledge syntheses are utterly distinct in comparison to those from systematic reviews. If provided, as in the present study, these implications may be limited in terms of providing advice from a clinical point of view. In short, scoping reviews are not customarily carried out for upholding the making of authoritative clinical guidelines but for advancing an overview of the nature and assortment of the evidence available. ${ }^{4}$

At the end of their Methods, Herman et al. ${ }^{1}$ stated that a metaanalysis will not be performed. However, they focused their analysis on pooling disease frequencies. ${ }^{1,8}$ If an included article reported continuous data as medians and interquartile ranges, means and SDs were estimated according to the method described by Wan et al. ${ }^{1,9}$ As the expert panel did not consider this item to be applicable for scoping reviews, PRISMA-ScR did not include summary measures in its checklist. ${ }^{2}$ Additional methods for quantitative synthesis have also been proposed. ${ }^{10}$ Furthermore, statistical methods for quantitative analysis of noncomparative series have already been described. ${ }^{8,10}$

\section{Results}

The authors screened 643 citations and excluded 288 (45\%) due to duplication. The remaining 355 citations were reviewed by title and abstract and 274 (77\%) did not meet eligibility criteria. From the 81 articles reviewed in full text, 49 (60\%) were excluded for different reasons (including outpatient setting and language restrictions, both $\mathrm{n}=2$ ). A total of 32 reports were considered for this scoping review. According to the prespecified aims, 22 and 11 articles were included in the final analyses of the first and second objectives, respectively. Of these articles, one was included in both analyzes. ${ }^{1}$ This description was depicted succinctly by the authors using a flow diagram, as recommended by the PRISMA-ScR reporting guidelines. ${ }^{2}$ The characteristics of evidence sources were displayed in detail using 2 tables. ${ }^{1}$

Regarding the first aim, this analysis included 20 retrospective studies, 1 prospective observational study, and 1 randomized controlled trial. Of these, most studies were conducted in China $(\mathrm{n}=20[90.9 \%])$. Altogether, in this analysis, 4,014 patients (mean age $55.6 \pm 8.4$ years) were included; $43 \%$ were women. The pooled frequency of preexisting neurologic conditions in adult inpatients with COVID-19 was $8.0 \%(n=322$ ) 4,014 [range 0\%-40\%] for individual studies). Among secondary outcomes, the authors also found that cerebrovascular disease (CVD) as a comorbidity was more likely in critically ill patients. Likewise, a history of CVD was more common in inpatients who did not improve or remit in the first 10 days. Acute respiratory distress syndrome was also more likely in patients with a history of CVD. Finally, a univariate analysis from a prospective cohort of patients with COVID-19 pneumonia showed that those with preexisting cardiovascular conditions (including CVD) had higher odds of death (odds ratio, 11 ; 95\% confidence interval, $4-30){ }^{1}$

Regarding the second aim, no pooled frequency of new-onset neurologic manifestations in adult inpatients infected with SARS-CoV-2 was reported. ${ }^{1}$ Among secondary outcomes, the authors also found that, in one retrospective study conducted in Wuhan, more than one-third $(36 \%)$ of patients $(n=214)$ developed a new neurologic symptom or event. Another retrospective study from Wuhan reported that $6 \%$ of inpatients with COVID-19 $(n=221)$ had an acute cerebrovascular event (including infarction, venous thrombosis, and hemorrhage). In a third retrospective study also conducted in Wuhan, hypoxic-ischemic encephalopathy was described in one-fifth of patients. In addition, delirium was reported in almost two-thirds (65\%) of critically ill patients in Strasbourg, France. Finally, the authors reported that additional newonset neurologic manifestations, such as acute necrotizing encephalopathy, seizures, Guillain-Barré syndrome, and meningoencephalitis, had been reported in isolated case reports.

\section{Interpretation: scoping vs systematic reviews}

One of the major findings from this scoping review is that $8 \%$ of adult inpatients with COVID-19 had at least one preexisting neurologic condition. This knowledge synthesis in addition suggested that patients with preexisting neurologic conditions (especially those with CVD) are prone to severe clinical courses when infected with SARS-CoV-2. It also indicated that more than one-third of inpatients with COVID-19 may have a new-onset neurologic manifestation during their admissions. Herman et al. ${ }^{1}$ concluded that a coordinated undertaking by the neurologic community is required to restructure clinical practices and thus serve the medical needs of patients during this season.

The main strength of this article is its selected methodology: scoping review. This method is especially fitting for examining emerging evidence, particularly when the prospect is still fuzzy and asking specific questions is challenging, which hinders the conduction of a proper systematic review. ${ }^{4}$ The scoping review methodology is therefore perfectly suitable to our current situation during this pandemic. Another strength of this article is the organization of studies included in the scoping review into 2 separate categories for synthesis: preexisting neurologic conditions and new-onset neurologic manifestations, respectively, both in adult inpatients with COVID-19. This step is termed grouping and its rational use in this evidence synthesis facilitates the understanding of both analyses and results.

Herman et al. ${ }^{1}$ identified several limitations of their scoping review, including small sample sizes, study designs, and overlapping publications. Nevertheless, most of these limitations are related to the nature and way of generating evidence 
during the pandemic. The acuity of this pandemic also limits the amount and quality of available neurologic information (including history, physical examination, and neuroimaging studies) in primary studies. Including only patients with COVID-19 who received inpatient treatment may also be a limitation in the scope of this synthesis, as this inclusion criterion excludes those who might have had either preexisting neurologic conditions or developed new neurologic complications but did not meet admission criteria. Another potential limitation is the lack of reporting of the method used to estimate the pooling disease frequencies. ${ }^{1}$ As the use of PRISMA-ScR is recommended for researchers, editors, and journals, an incomplete adherence to PRISMA-ScR reporting guidelines may be also regarded as a limitation of this scoping review. ${ }^{1}$

Given the methodology used, the clinical implications of this review are not immediate. As a whole, this study informs our practice by providing us a brief synthesis of the latest evidence on COVID-19 and neurology, and likewise it will help us to manage, in a better and more informed way, the challenges we currently endure worldwide.

\section{Study funding}

Guillermo Delgado-Garcia was supported by a full national scholarship from the Consejo Nacional de Ciencia y Tecnologia (Conacyt) to pursue his MSc degree (CVU: 613905).

\section{Disclosure}

G. Delgado-García is an editorial team member of the Neurology ${ }^{\circledR}$ Resident \& Fellow Section. A. Arauz and T. Corona report no disclosures relevant to the article. Go to Neurology. org/ $\mathrm{N}$ for full disclosures.

\begin{tabular}{lll} 
Appendix & Authors & \\
\hline Name & Location & Contribution \\
\hline $\begin{array}{l}\text { Guillermo } \\
\text { Delgado- } \\
\text { García, MD }\end{array}$ & $\begin{array}{l}\text { Instituto Nacional de } \\
\text { Neurologia y }\end{array}$ & $\begin{array}{l}\text { Designed and conceptualized } \\
\text { study, analyzed the data, } \\
\text { interpreted the data, drafted } \\
\text { the manuscript for intellectual } \\
\text { content }\end{array}$ \\
\hline $\begin{array}{l}\text { Antonio } \\
\text { Arauz, MD, } \\
\text { PhD }\end{array}$ & $\begin{array}{l}\text { Instituto Nacional de } \\
\text { Neurologia y }\end{array}$ & $\begin{array}{l}\text { Analyzed the data, interpreted } \\
\text { the data, revised the } \\
\text { manuscript for intellectual } \\
\text { content }\end{array}$ \\
\hline $\begin{array}{l}\text { Teresa } \\
\text { Corona, MD, } \\
\text { MSc }\end{array}$ & $\begin{array}{l}\text { Instituto Nacional de } \\
\text { Neurologia y }\end{array}$ & $\begin{array}{l}\text { Analyzed the data, interpreted } \\
\text { the data, revised the } \\
\text { manuscript for intellectual } \\
\text { content }\end{array}$ \\
\hline
\end{tabular}

\section{References}

1. Herman C, Mayer K, Sarwal A. Scoping review of prevalence of neurologic comorbidities in patients hospitalized for COVID-19. Neurology 2020;95:77-84.

2. Tricco AC, Lillie E, Zarin W, et al. PRISMA extension for scoping reviews (PRISMAScR): checklist and explanation. Ann Intern Med 2018;169:467-473.

3. Munn Z, Peters MDJ, Stern C, Tufanaru C, McArthur A, Aromataris E. Systematic review or scoping review? Guidance for authors when choosing between a systematic or scoping review approach. BMC Med Res Methodol 2018;18:143.

4. Peters MDJ, Godfrey C, McInerney P, Munn Z, Tricco AC, Khalil H. Scoping reviews (2020 version). In: Aromataris E, Munn Z, eds. Joanna Briggs Institute Reviewer's Manual. JBI; 2020. Available at: reviewersmanual.joannabriggs.org/

5. Paez A. Gray literature: an important resource in systematic reviews. J Evid Based Med 2017;10:233-240.

6. Higgins JPT, Thomas J, Chandler J, et al. Searching for and selecting studies. In: Higgins JPT, Thomas J, Chandler J, et al, eds. Cochrane Handbook for Systematic Reviews of Interventions, 2nd ed. Hoboken: Cochrane Collaboration/John Wiley \& Sons; 2019.

7. Stoll CRT, Izadi S, Fowler S, Green P, Suls J, Colditz GA. The value of a second reviewer for study selection in systematic reviews. Res Synth Methods 2019;10:539-545.

8. Barendregt JJ, Doi SA, Lee YY, Norman RE, Vos T. Meta-analysis of prevalence. J Epidemiol Community Health 2013;67:974-978.

9. Wan X, Wang W, Liu J, Tong T. Estimating the sample mean and standard deviation from the sample size, median, range and/or interquartile range. BMC Med Res Methodol 2014;14:135.

10. Murad MH, Sultan S, Haffar S, Bazerbachi F. Methodological quality and synthesis of case series and case reports. BMJ Evid Based Med 2018;23:60-63.

\section{Disputes \& Debates: Rapid online correspondence}

The editors encourage comments on recent articles through Disputes \& Debates:

Access an article at Neurology.org/ $N$ and click on "MAKE COMMENT" beneath the article header. Responses will be posted as rapidly as possible.

Before submitting a comment to Disputes \& Debates, remember the following:

- Disputes \& Debates is restricted to comments about articles published in Neurology within the last 8 weeks

- Read previously posted comments; redundant comments will not be posted

- Your submission must be 200 words or less and have a maximum of 5 references; the first reference must be the article on which you are commenting

- You can include a maximum of 5 authors (including yourself) 


\section{Neurology}

\section{Journal Club: Scoping review of prevalence of neurologic comorbidities in patients hospitalized for COVID-19}

Guillermo Delgado-García, Antonio Arauz and Teresa Corona

Neurology 2020;95;701-704 Published Online before print July 29, 2020

DOI 10.1212/WNL.0000000000010534

This information is current as of July 29, 2020

\section{Updated Information \& Services}

References

Subspecialty Collections

Permissions \& Licensing

Reprints including high resolution figures, can be found at: http://n.neurology.org/content/95/15/701.full

This article cites 8 articles, 3 of which you can access for free at: http://n.neurology.org/content/95/15/701.full\#ref-list-1

This article, along with others on similar topics, appears in the following collection(s):

All Medical/Systemic disease

http://n.neurology.org/cgi/collection/all_medical_systemic_disease Other Education

http://n.neurology.org/cgi/collection/other_education

Post-infectious

http://n.neurology.org/cgi/collection/postinfectious_

Information about reproducing this article in parts (figures,tables) or in its entirety can be found online at:

http://www.neurology.org/about/about_the_journal\#permissions

Information about ordering reprints can be found online:

http://n.neurology.org/subscribers/advertise

Neurology ${ }^{\circledR}$ is the official journal of the American Academy of Neurology. Published continuously since 1951, it is now a weekly with 48 issues per year. Copyright @ 2020 American Academy of Neurology. All rights reserved. Print ISSN: 0028-3878. Online ISSN: 1526-632X.

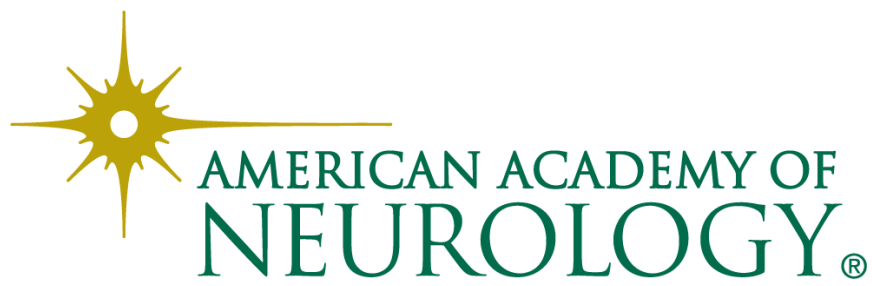

